UDC 1:316:114

LBC 87.6

\title{
REGIONAL TEXT AS A FACTOR OF ORGANIZING MODERN SOCIAL SPACE
}

\author{
Victoria A. Khrapova \\ Volgograd State University, Volgograd, Russian Federation
}

\begin{abstract}
In the context of modern social transformation, the role of regions as territorial-economic complexes and administrative units, gaining the status of entities in the national system of relations, is strengthening. Important indicators of the formation of the region are regional culture and regional self-awareness, due to the commonality of experiences of significant events occurring in a certain territory at a certain time. The key values of the regional culture are fixed in the regional text - a symbolic complex that accumulates the concepts of regional culture. The specificity of the regional text is due to its formation bades on local symbolic and symbolic structures with explanatory potential and translating the idea of stability, reliability, and also, to a large extent, development in the media environment, dissemination in the media format that informs the regional text of innovative qualities that former media (mobility, flexibility, interactivity, fundamental openness at the semantic and structural-compositional levels) didn't have. The regional text carries an identification code, it contains life-preserving constants and lifesetting values. Possessing a built-in mechanism for the correction of semantic and syntactic relations, aimed at self-preservation of the social whole, the regional text performs constructive and projective functions in the context of modern social dynamics. Sign-symbolic complexes with regional semantics play an important role in the self-description of regional communities, allowing them to maintain self-identification, to recreate the conditions necessary for optimal interaction and life in the modern social space. The regional text plays a large role in shaping the image of the region, which determines its socio-economic status and cultural status. The modern regional text is mobile, multi-layered, discrete, and has no rigid structure. It is synergistically transforming into a dynamically changing society, depending on the goals and values that guide the regional community. The presence of control parameters in the structure of the regional text makes it an important factor in sustainable development and determines the need for the conscious participation of the political and intellectual elite in the creation of regional semiotic spaces.
\end{abstract}

Key words: region, text, communication, social dynamics, transformation.

УДК 1:316:114

ББК 87.6

\section{РЕГИОНАЛЬНЫЙ ТЕКСТ КАК ФАКТОР ОРГАНИЗАЦИИ СОВРЕМЕННОГО СОЦИАЛЬНОГО ПРОСТРАНСТВА}

\author{
Виктория Анатольевна Храпова \\ Волгоградский государственный университет, г. Волгоград, Российская Федерация
}

\begin{abstract}
Аннотация. В условиях современной социальной трансформации усиливается роль регионов как территориально-хозяйственных комплексов и административных единиц, обретающих статус субъектов в общеح государственной системе отношений. Важными показателями становления региона являются региональные 공 культура и самосознание, обусловленные общностью переживаний значимых событий, происходящих на ¿ определенной территории в определенное время. Ключевые ценности региональной культуры фиксируют๓ ся в региональном тексте - знаково-символическом комплексе, аккумулирующем в себе концепты региональной культуры. Специфика регионального текста обусловлена его формированием на базе локальных знаково-символических структур, обладающих объяснительным потенциалом и транслирующих идею устойчивости, стабильности, надежности, а также в значительной степени развитием в медиасреде, распрост() ранением в медиаформате, сообщающем региональному тексту инновационные качества, которых не было
\end{abstract}


у прежних носителей информации (мобильность, пластичность, интерактивность, принципиальная открытость на смысловом и структурно-композиционном уровнях). Региональный текст несет в себе идентификационный код, в нем заложены жизнесохраняющие константы и жизнеустроительные ценности. Обладая встроенным механизмом коррекции семантических и синтаксических связей, направленный на самосохранение социального целого региональный текст выполняет конструктивные и проективные функции в условиях современной социальной динамики. Знаково-символические комплексы с региональной семантикой играют важную роль в самоописании региональных сообществ, позволяя им поддерживать самоидетнтификацию, воссоздавать состояния, необходимые для оптимального взаимодействия и жизнедеятельности в современном социальном пространстве. Региональный текст играет большую роль в формировании образа региона, определяющего его социально-экономическое положение и культурный статус. Современный региональный текст подвижен, многослоен, дискретен, не имеет жесткой структуры. Он синергетически преобразуется в динамично меняющемся социуме в зависимости от целей и ценностей, которыми руководствуется региональное сообщество. Наличие управляющих параметров в структуре регионального текста делает его важным фактором устойчивого развития и определяет необходимость осознанного участия политической и интеллектуальной элиты в создании региональных семиотических пространств.

Ключевые слова: регион, текст, коммуникация, социальная динамика, трансформация.

Реализуя потребность в фиксации опыта и трансляции полученной в процессе познания информации с целью организации жизненного пространства, люди создавали разные типы знаково-символических структур, очерчивающих картину мира, определяющих характер восприятия, особенности мышления и социального взаимодействия. Каждая историческая эпоха создавала свои формы описания, обладающие объяснительной силой и организующим потенциалом.

В современном интенсивно развивающемся трансформирующемся мире усиливается роль регионов - хозяйственно-экономических комплексов и административно-территориальных единиц, обретающих статус субъектов в общегосударственной системе [Храпова 2017]. Определяющим этапом в становлении региона является образование региональной культуры - «особой формы бытия социума и человека в заданных пространственных координатах, которая опирается на историческую традицию, формирует систему ценностей, продуцируя особый тип личности» [Мурзина 2004, 89-90]. Важным индикатором региональной культуры является региональное самосознание, обусловленное общностью переживаний группой людей социально-исторических событий, происходящих на определенной территории и в определенное время - в том контексте, который определяет специфику восприятия событий. Региональная культура представляет собой «сложный конгломерат взаимодействующих явлений, она тесно связана с этнической культурой, но имеет свой путь исторического развития, является уникальным сочетанием традиций инноваций. Будучи важным фактором духовного, политического и социально-экономического развития регионов, региональная культура одновременно является и стратегическим ресурсом государства, выступает главным инструментом для достижения устойчивого развития на всех уровнях» [Яковлева web].

Ключевой элемент региональной культуры - региональный текст. Его основу составляет совокупность локальных текстов, которые хранят в себе семантический и идеологический код, фиксирующий информацию о своеобразии пространства, позволяя его идентифицировать. Как правило, локальный текст описывает историю места, обладающую мифологическим и символическим смыслом. Это нарратив, предсказывающий состояния, которые могут ожидать человека, оказавшегося в данной части пространства. Источниками локальных текстов выступают краеведческие исследования, визуальные образы среды, художественные произведения, содержание которых включает в себя описание или образное осмысление реалий ландшафта, дискурсивные практики, обслуживающие повседневность. Формирующиеся в процессе освоения людьми уникальной части земного ландшафта знаковосимволические структуры фиксируют естественность связи человека, природы и общества, их органичной целостности, что сообщает локальным текстам идею стабильности и надежности, делая их особенно актуальными и востребованными в периоды трансформаций. 


\section{НАУЧНЫЕ СООБЩЕНИЯ}

В настоящее время изменились когнитивные контексты развития и функционирования знаково-символических структур с локальной семантикой. Конституирующие их мифы и символы стали «восприниматься, воображаться, конструироваться и деконструироваться в рамках целенаправленных актов сознания, стремящихся к оконтуриванию, фиксации оригинальных метагеографических пространств с целью маркетинга территорий и мест, в социокультурном проектировании, стратегическом планировании и брендинге территорий, региональном политологическом анализе и т. д.» [Замятин web]. Локальные мифы перестали быть традиционными нарративами, характеризующими определенные территории. Они стали «принципиально, жизненно, экзистенциально важными компонентами ви́дения не только прошлого и настоящего, а также и будущего - будущее начинает как бы закрепляться, “фиксироваться” соответствующими легендарными событиями и историями, уверенно проецируемыми в пространство еще не сбывшегося, не состоявшегося, однако весьма возможного и желательного» [Замятин 2010, 32].

Важнейшую роль в организации современного социального пространства играют медиаструктуры. СМИ создают свою логику производства знаний и осуществления событий, свой режим времени и формат пространства, задавая параметры организации социальной реальности, мотивируя социальную и культурную динамику в глобальном масштабе [Полонский 2015].

Основной единицей организованного СМИ медиапотока является медиатекст. Формирующийся на базе современных информационных технологий, он несет в себе инновационные качества, которых не было в прежних носителях информации.

Мультимедийные технологии способствуют созданию семиотически осложненных (полисемиотических) знаково-символических структур, в которых объединены синергетически взаимодействующие слово, изображение и звук [Мардиева 2014]. При этом фокус мультимедийного текста находится в сфере визуального послания. Если вербальный текст, как правило, содержит аргументацию, апеллирующую к интеллектуаль- но-понятийным и ценностным смыслам, то невербальная составляющая, включающая в себя различные приемы и техники коммуникации, стимулирует эмоциональную реакцию аудитории и создает, главным образом, отношение - эмоциональный отклик на информацию, события, факты.

Уникальной способностью медиатекста, сформированного на базе цифровых технологий, является пластичность - легкое производство, быстрая трансляция, мгновенная трансформация, возможность бесконфликтного объединения в едином пространстве различающихся в смысловом и семиотическом планах дискурсов. Медиатекст - интегративное многоуровневое образование, объединяющее в единое коммуникативное целое разные семиотические коды и принципиально открытое как на содержательно-смысловом, так и на композиционно-структурном уровне.

В обращенной к массовой аудитории медиасреде традиционные тексты систематизируются, трансформируются компануются по принципу гиперструктуры, сети, позволяющей адресатам самим избирать значения и создавать принципы формирования смысла.

Благодаря современным технологиям текст массовой коммуникации приобрел интерактивные свойства: аудитория получила возможность оперативно реагировать на получаемые сообщения, комментировать их, кроме того, сам диалог сознаний автора и адресата становится доступным для всеобщего наблюдения и оценки. Специфический характер массмедийной интертекстуальности создает принципиальную незавершенность смысловых пространств.

Как было замечено А.В. Полонским, в процесс информационно-смыслового обмена посредством масс-медиа сегодня активно включились не только специалисты в сфере рекламы и связей с общественностью, но и представители других специальностей: врачи и преподаватели, ученые и политики, профессионалы и любители в сфере искусств, моды, дизайна, специалисты в области музейной и выставочной деятельности, информационных технологий, экономики и маркетинга [Полонский 2015]. Включаясь в медийную среду, создавая медиатексты, многие авторы проявляют заинтересованно-вдумчивое отноше- 
ние к миру, внимание к потребностям и эстетическим чувствам человека.

В.В. Хорольский обратил внимание на то, что медийные тексты существуют как спонтанно возникающая и саморазвивающаяся синергетическая часть социального макродискурса повседневности. Предназначенные для массовой аудитории, рассредоточенной, неопределенной, разнородной, не связанной интересами, целями и ценностями, они стремятся быть ближе к этой аудитории, мотивируются «прагматикой продвижения», которая основывается на внимательном отношении к культурнопсихологическим особенностям, когнитивным, познавательным, творческим, эмоциональным способностям людей [Хорольский 2013, 22].

Гибко приспосабливаясь к запросам, тонко настраиваясь на движение мысли и чувств, СМИ мягко вовлекают людей в поле своего действия, удерживая внимание и корректируя интересы и потребности социальных групп, определяя вектор движения мысли.

В медийной среде происходит не только осмысление локальных историй, значимых сюжетов и символов, но и анализ концептуального оформления представляющих историю нарративов, вырабатывается внимательное и ответственное отношение к ценностям, которыми нужно руководствоваться в процессе создания информационного контента.

При всем многообразии и вариативности форм медийный текст можно считать культурным текстом, характеризующим специфику современности, носителем специфических кодов и содержаний, реализующих определенную миссию. Как представляется В.В. Хорольскому, миссия эта - объединять разные по своей смысловой направленности тексты, быть «модератором всеобщего форума». «Миссия всех работников медиасферы обусловлена единой целью - знать о мире как можно больше, отбирать самое нужное и интересное для аудитории, на которую работаешь, но при этом помнить о высшем долге, о служении Истине, о соединении разнородной аудитории на платформе общечеловеческих ценностей» [Хорольский 2013, 83].

Формирование и развитие регионального текста происходит в медийной среде, под воздействием «установок» и практик, соответствующих современному этапу социально- го развития. Распространяемые по медиаканалам региональные тексты предстают как синергетические образования, предполагающие активную интерпретацию, сотворчество, инновационные по своей природе. Организуемый в медиасреде контекст не несет в себе жестко закрепленного идеологического содержания, легко соединяя локальное и глобальное. Локальные мифологии и истории метафоризируют пространства, способствуя развитию, разрастанию новых семантик возможных миров, формируя транслокальную идентичность. Таким образом, по мнению А.В. Полонского, создается ментальный и онтологический фундамент нового культурного ландшафта [Полонский 2015, 38].

Как правило, смыслы регионального масштаба концентрируются в региональном центре - городе, обретающем статус неформальной столицы данного региона. Исторически город формируется как рациональное упорядочивание пространства, начинается с ограды-границы, разделяющей неосвоенное и освоенное, порядок и хаос. Город концентрирует в себе ресурсы и ценности.

Современный полистилистичный город предстает как открывающаяся в переломные эпохи трансцендентность. Семантическая нагруженность и эмоциональное напряжение провоцируют человека делать выбор, рисковать, совершать поступки и находить новые шансы. Городская среда предполагает возможность выбора новых критериев создания целого - архитектурного, социокультурного, идейного. М. Лурье в анонсе к своим лекциям о городском пространстве писал: «Всякий город представляет собой не только сложный социально-экономический организм, но и определяющий фактор существования локального сообщества и одновременно предмет постоянной рефлексии этого сообщества. Элементы городского пространства и инфраструктуры, события и персонажи истории и текущей жизни города, различные группы населения и городские институции, экономические, административные, градостроительные изменения, происходящие в городе, - все это наделяется в местной культурной традиции определенными смыслами и оценками, из которых одни - подвижны и сиюминутны, а другие - устойчивы и долговечны. Отдельные 


\section{НАУЧНЫЕ СООБЩЕНИЯ}

представления о том или ином городе рассчитаны на внешнего потребителя, и некоторые из них становятся фактом общенациональной или мировой культуры, однако большинство существует «для внутреннего пользования» и имеет хождение в пределах самого сообщества горожан, выражаясь в многообразных текстах и практиках» [Локальный текст... web].

Региональное пространство может восприниматься как провинциальное - архаичное, инертное, зависимое в политическом и экономическом планах, а может быть политически лояльным, но исторически самобытным, самодостаточным в экономическом отношении, сохраняющим культурную идентичность. Чаще всего региональные центры, проявляя столичную амбициозность, стремятся к самоутверждению через сохранение жизнетворческих смыслов, сосредоточенных в провинции.

Региональное сообщество нуждается в описании, позволяющем гордиться своим происхождением, поддерживать идентификацию, создавать дискурсивное пространство, вызывающее положительные эмоции и состояния. История города, его ценности, знаки и символы способствуют созданию образа города, его ключевой идеи, которая может оказывать влияние на социальные практики. Транслируемый в региональном тексте образ региона - это одновременно и результат преобразования регионального пространства, основывающегося на видении региональным сообществом культурного наследия, своей истории, прошлого, и образ желаемого будущего, проекция позиции, которая выбирается для самоопределения в соответствии с целями и средствами социально-экономического и культурного развития. Региональный текст является совокупным итогом многочисленных осмыслений событий современного мира, он синергетически преобразуется в ситуациях, требующих совместных усилий для осознания и интерпретации [Яковлева 2017]. Таким образом, в современном коммуникативном пространстве региональный текст выполняет обобщающие, структурирующие, связующие функции, то есть выступает в качестве метатекста, благодаря которому происходит рефлексия над другими культурными текстами и создаются условия для сохранения социального целого.

\section{СПИСОК ЛИТЕРАТУРЫ}

Замятин web- Замятин Д.Н. Локальные мифы и географическое воображение [Интелрос] // http:// www.intelros.ru/subject/figures/dmitriy-zamyatin/ 12250-lokalnye-mify-modern-i-geograficheskoevoobrazhenie.html.

Замятин 2010 - Замятин Д.Н. Гуманитарная география: пространство, воображение и взаимодействие современных гуманитарных наук // Социол. обозрение. 2010. Т. 9, № 3. С. 26-50.

Локальный текст... web - Локальный текст современного провинциального города (на материале полевых исследований в городах Подолии) // https://sefer.ru/rus/education/educa tional_programmes/polevie issledovania v_Podolii.php?fbclid=IwAR2 gHl1 i $7 \mathrm{roVu}_{-}$ tY̌gHp506eRNG2CZt8rBcXws YouFmLB gwR4CUn3wjx5o-k.

Мардиева 2014 - Мардиева Л.А. Коды визуального поведения и прецедентные визуальные феномены в составе семиотически осложненных текстов средств массовой информации // Полит. лингвистика. 2014. № 2 (48). С. 246-249.

Мурзина 2004 - Мурзина И.Я. Региональная культура как предмет философско-культурологического исследования // Известия Урал. гос. ун-та. Проблемы образования, науки и культуры. 2004. Вып. 15, № 29. С. 60-78.

Полонский 2015 - Полонский А.В. Медиа и их текстовая реальность // Науч. ведомости. Сер.: Гуманит. науки. 2015. Вып. 27, № 8(215). С. 17-24.

Хорольский 2013 - Хорольский В.В. Медийность в текстах СМИ и понятие медийного модуля // Вестник Моск. ун-та. Сер. 10, Журналистика. 2013. № 4. С. 75-88.

Храпова 2017 - Храпова В.А. Регионализм как форма проявления субъектности (феноменологический взгляд на герменевтические исследования М. Фуко) // Вестник Волгоградского государственного университета. Серия 7 , Философия. Социология и социальные технологии. 2017. Т. 16. № 1. С. 110115. DOI: https://doi.org/10.15688/ jvolsu7.2017.1.12.

Яковлева 2017 - Яковлева Е.Л. Современное видение интерпретационной модели текста // Litera. 2017. № 1. C. 57-66. DOI: https://doi.org/10.7256/ 2409-8698.2017.1.21657.

Яковлева web - Яковлева Е.Н. К определению понятия «региональная культура» [Ученые записки. Электрон. науч. журн. Курского ун-та. 2013. № 4 (28). C. 256-262] // https://cyberleninka.ru/ article/n/k-opredeleniyu-ponyatiyaregionalnaya-kultura/viewer. 
B.A. Храпова. Региональный текст как фактор организации современного социального пространства

\section{REFERENCES}

Zamyatin D.N. Local Myths and Geographical Imagination. Interlos. URL: http://www.intelros.ru /subject/figures/dmitriy-zamyatin/12250-lokalnyemify-modern-i-geograficheskoe-voobrazhenie.html.

Zamyatin D.N., 2010. Humanities Geography: Space, Imagination and Interaction of Modern Humanities. Sotsiologicheskoe obozrenie, vol. 9, no. 3, pp. 26-50.

Local Text of a Modern Provincial Town (On the Material of Field Research in the Cities of Podolia). URL: https://sefer.ru/rus/education/ educational_programmes/polevie issledovania_v_Podolii.php?fbclid $=\mathrm{Iw} \overline{\mathrm{A}}$ R2gH11i7roVu_tYgHp506eRNG2CZt8r BcXwsYouFmLBgwR4CUn3wjx5o-k.

Mardieva L.A., 2014. Codes of Visual Behavior and Precedent Visual Phenomena in Semiotically Complicated Media Texts. Politicheskaya lingvistika, no. 2 (48), pp. 246-249.

Murzina I.Ya., 2004. Regional Culture as a Subject of Philosophical and Cultural Research. Izvestiya Uralskogo gosudarstvennogo universiteta.
Problemy obrazovaniya, nauki i kultury, iss. 15, no. 29, pp. 60-78.

Polonskij A.V., 2015. Media and Their Textual Reality. Nauchnye vedomosti. Seriya. Seriya Gumanitarnye nauki, iss. 27, no. 8(215), pp. 17-24.

Horol'skijV.V., 2013. Media in Media Texts and the Concept of a Media Module. Vestnik Moskovskogo universiteta. Seriya 10. Zhurnalistika, no. 4, pp. 75-88.

Hrapova V.A., 2017. Regionalism as a Form of Manifestation of Subjectivity (a Phenomenological View of M. Foucault's Hermeneutic Studies). Vestnik Volgogradskogo gosudarstvennogo universiteta. Seriya 7. Filosofiya. Sociologiya i social'nye tekhnologii, vol. 16, no. 1,pp. 110-115. DOI: https:// doi.org/10.15688/jvolsu7.2017.1.12.

Yakovleva E.L., 2017. Modern Vision of the Interpretive Model of Text. Litera, no. 1, pp. 57-66. DOI: https://doi.org/10.7256/2409-8698.2017.1.21657. Yakovleva E.N., 2013. To the Definition of "Regional culture". Uchenye zapiski. Elektronnyj nauchnyj zhurnal Kurskogo universiteta, no. 4 (28), pp. 256262. URL: https://cyberleninka.ru/article/n/kopredeleniyu-ponyatiya-regionalnaya-kultura/ viewer.

\section{Information About the Author}

Victoria A. Khrapova, Doctor of Sciences (Philosophy), Associate Professor, Professor of the Department of Philosophy, Volgograd State University, Universitetsky Prosp., 100, 400062 Volgograd, Russian Federation, khrapova@volsu.ru, https://orcid.org/0000-0002-5236-9147

\section{Информация об авторе}

Виктория Анатольевна Храпова, доктор философских наук, доцент, профессор кафедры философии, Волгоградский государственный университет, просп. Университетский, 100, 400062 г. Волгоград, Российская Федерация, khrapova@volsu.ru, https://orcid.org/0000-0002-5236-9147 